\title{
Does Management of Lipid Lowering Differ Between Specialists and Primary Care: Insights from GOAL Canada.
}

\author{
Anatoly Langer ${ }^{1}$, Mary $\operatorname{Tan}^{1}$, Shaun Goodman ${ }^{2}$, Jean Gregoire ${ }^{3}$, Peter $\operatorname{Lin}^{1}$, John \\ Mancini $^{4}$, James Stone ${ }^{5}$, and Lawrence Leiter ${ }^{6}$ \\ ${ }^{1}$ Canadian Heart Research Centre \\ ${ }^{2}$ St Michael's Hospital \\ ${ }^{3}$ Université de Montréal, Institut de cardiologie de Montréal \\ ${ }^{4} \mathrm{UBC}$ \\ ${ }^{5}$ Cumming School of Medicine, University of Calgary; Libin Cardiovascular Institute of \\ Alberta \\ ${ }^{6}$ St Michael's Hospital and University of Toronto
}

October 5, 2020

\begin{abstract}
Background: We studied whether significant differences in care gaps exist between specialists and PCPs. Methods: GOAL Canada enrolled patients with CVD or familial hypercholesterolemia (FH) and LDL-C > 2.0 mmol/L despite maximally tolerated statin therapy. During follow-up, physicians received online reminders of treatment recommendations based on Canadian Guidelines. Results: A total of 177 physicians ( $58 \%$ PCPs) enrolled 2009 patients; approximately half of the patients were enrolled by each physician group. Patients enrolled by specialists were slightly older (mean age 63 years vs. 62), female (45\% vs. $40 \%$ ), Caucasian ( $77 \%$ vs. $65 \%$ ), and had a slightly higher systolic pressure and lower heart rate. Patients enrolled by specialists had less frequent history of familial hypercholesterolemia, diabetes, hypertension, chronic kidney disease and liver disease but more frequent history of coronary artery disease, atrial fibrillation and premature family history of CVD. There was no significant baseline difference in LDL-C, HDL-C, or non-HDL-c, although total cholesterol and triglycerides were slightly higher in patients managed by PCPs. At baseline, PCPs were more likely to use statins ( $80 \%$ vs.73\%, p=0.0002) and other therapies such as niacin or fibrate $(10 \%$ vs. $6 \%, \mathrm{p}=0.0006)$ but similar use of ezetimibe $(24 \%$ vs. $27 \%, \mathrm{p}=0.15)$. At the end of follow up, specialists used less statins ( $70 \%$ vs. $77 \%, \mathrm{p}=0.0005)$ and other therapies $(6 \%$ vs. $10 \%, \mathrm{p}=0.007)$ but more ezetimibe ( $45 \%$ vs. $38 \%, p=0.01)$ and the same frequency of PCSK9i $(28 \%$ vs. $27 \%, \mathrm{p}=0.65)$. The proportion of patients achieving the recommended LDL-C level of $2.0 \mathrm{mmol} / \mathrm{L}$ or below (primary endpoint) was similar at last available visit between specialists and PCPs (44\% vs. $42 \%, \mathrm{p}=0.32$ ). Conclusion: Despite minor differences in the clinical profile of their patients, both PCPs and specialists actively participate in the management of lipid lowering therapy in high risk CVD patients and experience similar challenges and care gaps.
\end{abstract}

\section{Introduction}

Low-density lipoprotein cholesterol (LDL-C) is a well-established risk factor for cardiovascular disease (CVD) and many guidelines recommend LDL-C lowering to reduce the risk of both cardiovascular events and mortality in patients with CV disease ${ }^{(1)}$ and familial hypercholesterolemia $(\mathrm{FH})$.

The 2016 Canadian Cardiovascular Society clinical practice guidelines (CPG) recommend initiation of LDL$\mathrm{C}$ lowering with high intensity statin therapy and the addition of ezetimibe or a PCSK9i as needed if LDL-C is not lowered by at least $50 \%$ or to a level below $2.0 \mathrm{mmol} / \mathrm{L}$ in patients with established CVD or FH. ${ }^{(2)}$. Despite specific and updated CPG, many patients fail to reach guideline-recommended levels ${ }^{(3-10)}$ GOAL 
Canada ${ }^{(11)}$ reported that physician education based on the reminder system significantly improved care as measured by the proportion of patients achieving the recommended LDL-C level in relation to a greater utilization of recommended ${ }^{(2)}$ lipid lowering therapies. CPG recommendations do not typically distinguish between the respective roles of primary care physicians (PCPs) or specialists; further, it is not known whether the adoption of guidelines, pattern of management and specific strategies for lowering LDL-C are different for these groups of physicians. This post hoc analysis of GOAL Canada ${ }^{(11)}$ aims to ascertain if any differences exist between PCPs and specialists with respect to the utilization of lipid lowering therapies.

\section{Methods}

The Guidelines Oriented Approach to Lipid lowering (GOAL) Canada ${ }^{(11)}$ was an interventional program supported by Amgen Canada. It was an investigator-initiated study started in 2015 and coordinated by the Canadian Heart Research Centre, an academic research and education physician organization. The intervention studied was physician education/lipid management reminders applied at the end of each of three visits based on data entry in the electronic case report form (eCRF). Participating physicians received fair market value compensation for completing the electronic case report form. The study was approved by central and institutional research ethics boards where appropriate and all enrolled patients provided informed consent.

Invitations to participate were sent to 750 Canadian physicians across Canada from a proprietary (CASL Regulation) Canadian Heart Research Centre list of physicians who participated in prior cholesterol-oriented data collection studies ${ }^{(12,13)}$ and 248 were activated to enrol their patients for whom the participating physicians had the primary role for cholesterol lowering management. These physicians were asked to consecutively enrol at least 12 of their patients with either (1) clinical vascular disease such as coronary artery disease $(\mathrm{CAD})$, cerebrovascular disease, abdominal aortic aneurysm, or peripheral arterial disease; or, (2) familial hypercholesterolemia (FH), as defined in the Canadian guidelines. (2). In addition, all patients had to have an LDL-C $>2.0 \mathrm{mmol} / \mathrm{L}$ despite maximally tolerated statin therapy (defined as having tried at least two statins, each at least on two reduced doses) for at least three months prior to enrolment. Patient outcomes for lipid lowering were assessed at baseline and twice more approximately 4-6 months apart. Physicians were asked to provide a single most important reason for each patient as to why the guidelines were not followed.

\section{Statistical Analysis}

Continuous data are shown as means with standard deviation and categorical data as frequencies and percentages. Group comparisons were made using the chi squared test and t test or Kruskal-Wallis test for discrete and continuous variables, respectively, where appropriate. We used repeated measures analysis to perform univariate and multivariable regression to determine the outcome across the visits. While the primary endpoint for GOAL Canada ${ }^{(11)}$ was the proportion of patients achieving the recommended LDL$\mathrm{C}$ level, the purpose of this analysis was a comparison between specialists and PCPs with respect to any differences in the primary endpoint and the use of additional recommended lipid lowering therapies.

Multivariable logistic regression model was developed to assess factors independently associated with LDL$\mathrm{C}$ achieving target of [?]2.0 mmol. The following variables were considered: variables in Table 1 with $\mathrm{p}<0.05$ and specialist or PCP group. To account for the clustering of patients within visits, we performed a generalized estimating equations (GEE) model. The working correlation structure selected was based on its lowest quasi-likelihood under the independence model criterion (QIC). Adjusted odds ratio (OR) with $95 \%$ confidence intervals (CI) are presented. A value of $\mathrm{P}<0.05$ was considered significant for all tests. All statistical analyses were performed in SAS software version 9.4 (SAS Institute, Cary, NC).

\section{Results}

A total of 177 physicians (102 PCPs and 75 specialists) enrolled 2009 patients; Ontario contributed more than any other province with the top 4 being Ontario, BC, Quebec, and Alberta. The number of patients enrolled by specialists and PCPs was equal. 
Patients enrolled by specialists were slightly older, more frequently female and Caucasian (77\% vs. 65\%, $\mathrm{p}=0.0001$ ) and with other differences in clinical characteristics summarized in Table 1. Specialists had less patients on statin therapy and bile acid sequestrants but more patients on aspirin and other antiplatelet therapies as well as beta blockers (Table 1). Patients treated by specialists had slightly lower total cholesterol and triglycerides but no difference in LDL-C or non-HDL-C levels (Table 1).

At baseline and during the follow up, the specialists tended to use less statins (Figure 1) but more additional and recommended non-statin therapy (Figure 1). PCPs used more of other, non-guideline recommended lipid lowering therapies such as niacin or fibrate as compared to specialists ( $10 \%$ vs. $6 \%, \mathrm{p}=0.007)$.

The mean LDL was $3.3 \mathrm{mmol} / \mathrm{L}$ at baseline (visit 1) and decreased significantly to 2.4 and $2.2 \mathrm{mmol} / \mathrm{L}$ respectively during the follow up in visits 2 and $3^{(11)}$, there was no difference in the extent of decrease between specialists and PCPs (Figure 2). The proportion of patients achieving the CCS recommended LDL$\mathrm{C}$ level of $<2.0 \mathrm{mmol} / \mathrm{L}$ (primary endpoint) increased significantly to $41.7 \%$ and $50.8 \%$ in visits 2 and 3 respectively ${ }^{(11)}$ and was similar between specialists and PCPs (Figure 3).

Physician responses as to why they were not following guidelines with respect to additional therapy of ezetimibe and/or PCSK9i are summarized in Figure 4; physicians did not provide reasons for not following the guidelines for each patient. The two most frequent reasons provided were patient refusal (more common by specialists) and additional therapy not perceived to be needed. Importantly, both groups of physicians (more often PCPs than specialists) stated that additional therapy would be prescribed at the next visit. Cost, as a reason for not following the guidelines was more commonly sited by PCPs while co-morbidities, patient intolerance, or social constraint was more frequently cited by specialists (Figure 4).

Multivariable analysis identified female gender, history of $\mathrm{FH}$ and chronic kidney disease as being associated with a lower likelihood of achieving recommended LDL-C level while age, coronary artery disease and diabetes as being predictors of achieving the recommended level. Care by a specialist vs. PCP was not significantly associated with achieving the recommended LDL-C level (1.02 [95\% CI: 0.87-1.20] p=0.80). The use of any recommended lipid lowering therapy was the strongest indicator of achieving LDL-C $<2.0 \mathrm{mmol} / \mathrm{L}$ with the odds ration and 95\% CI for statin 3.10 (2.54-3.78, $\mathrm{p}<.0001)$, ezetimibe $1.71(1.46-2.01, \mathrm{p}<.0001)$ and PCSK9i 17.21 (13.69-21.63, p <.0001).

\section{Discussion}

Established CVD and FH are both associated with major adverse cardiovascular morbidity and mortality. Aggressive lowering of LDL-C has been shown to reduce the risk of cardiovascular events and mortality in both of these groups $(28,18.19)$. Despite the use of high intensity statin therapy, many patients do not achieve the recommended LDL-C level. The addition of second and third-line therapies has been shown to reduce residual cardiovascular risk. ${ }^{(28,18,19)}$. Reminders to physicians to adhere to CPG treatment targets was recently shown to result in more patients achieving the recommended LDL-C in both patients with established CVD and $\mathrm{FH}^{(11)}$.

This analysis of the GOAL Canada study ${ }^{(11)}$ compared management by specialists and PCPs with respect to their following of the guidelines recommendations. The proportion of patients enrolled by specialists and PCPs turned out to be very close, a serendipitous outcome, which provided an excellent opportunity for this comparison. No difference in the achievement of the recommended LDL-C level or reduction in the LDL-C during follow up was seen between the specialist and PCP groups and this finding was further supported on the multivariable analysis.

A number of important care gaps were identified. At baseline, a significant proportion of patients were not treated with any statin therapy which suggests a knowledge gap and physician unfamiliarity with establishing and maintaining statin use, while dealing with potential statin intolerance. What was even more surprising is that the proportion of patients not on statin therapy was significantly greater among specialists. One can speculate that perhaps the patients followed by specialists were more likely to have statin tolerability issues. On the other hand, specialists were more likely to use recommended additional therapy such as ezetimibe 
and/or PCSK9i. However, there was no difference between the specialists and PCP groups in lowering of the LDL-C during follow up or in the proportion of patients achieving the recommended LDL-C level, despite this greater use. Previous comparisons using administrative database for diabetes care, also revealed a care gap of similar proportions between specialist and PCP care. ${ }^{(29)}$

Additional evidence of a knowledge gap is revealed by physician responses regarding why recommended therapy was not being used.The second most common reason for not following the guidelines was that additional therapy was not needed despite the LDL-C being clearly above the recommended level. This is the clearest example of a knowledge gap or a manifestation of treatment inertia for both groups of physicians and requires additional per-to-peer education. Patient intolerance was the most frequent response by specialists and PCPs and raises a question of how well patients are informed about their personal cost of non-adherence. Given there was no significant difference in this response between PCPs and specialists, strongly suggests how difficult patient non-adherence will be to address.

A response by physicians confirming that additional recommended therapy will be prescribed at the next visit was more frequent with PCPs and is an example of an action gap indicating treatment inertia coupled with a realization that adherence with guidelines improves care. Addressing the challenges that have prevented physicians from optimizing therapy before the reminder is important in closing the care gap.

\section{Limitations}

This post-hoc analysis is subject to physician selection and participation bias, however, if the bias is operative in a similar fashion for PCPs and specialists, our findings are balanced, though not necessarily representative of the overall physician population. Selection bias may have also resulted in the selection of physicians who were interested in cholesterol lowering through their prior participation in similar programs. If this selection bias was present then our findings of the care gap are even more pronounced indicating treatment inertia even among those more likely to be skilled in the art of LDL-C lowering.

\section{Conclusion}

Specialists and PCPs have a complimentary role to play in the management of patients with cardiovascular disease with respect to lipid lowering therapy and both groups exhibit similar treatment inertia. Important knowledge and action care gaps require additional education and support systems, respectively, in order to optimize care and overcome barriers contributing to optimal care.

\section{Table and Figure Legends}

Table 1: Clinical baseline characteristics

Figure 1: The use of ezetimibe and PCSK9 inhibitor at baseline and during follow up

Figure 2: Changes in LDL-C with follow up

Figure 3: Proportion of patients achieving recommended LDL-C level $<2 \mathrm{mmol} / \mathrm{L}$

Figure 4: Reasons for not following the recommended therapy

\section{References}

1. Baigent C, Keech A, Kearney PM, et al; Cholesterol Treatment Trialists (CTT) Collaborators. Efficacy and safety of cholesterol-lowering treatment: prospective meta-analysis of data from 90,056 participants in 14 randomised trials of statins. Lancet 2005;366:1267-78.

2. Anderson TJ, Gregoire J, Pearson GJ et al. 2016 Canadian Cardiovascular Society Guidelines for the Management of Dyslipidemia for the Prevention of Cardiovascular Disease in the Adult. Can J Cardiol 2016;32:1263-82.

3. Waters DD, Brotons C, Chiang CW, et al. Lipid Treatment Assessment Project 2:Amultinational survey to evaluate the proportion of patients achieving low-density lipoprotein cholesterol goals. Circulation 
2009;120:28-34.

4. Saposnik G, Goodman SG, Leiter LA, et al. Applying the evidence: Do patients with stroke, coronary artery disease, or both achieve similar treatment goals? Stroke 2009;40:1417-24.

5. Hackam DG, Leiter LA, Yan AT, et al. Missed opportunities for secondary prevention of cardiovascular disease in Canada. Can J Cardiol 2007; 23:1124-30.

6. Yan AT, Yan RT, Tan M, et al. Contemporary management of dyslipidemia in high-risk patients: targets still not met. Am J Med 2006;119:676-83.

7. Banegas JR, Vegazo O, Serrano P, et al. The gap between dyslipidemia control perceived by physicians and objective control patterns in Spain. Atherosclerosis 2006;188:420-4.

8. Ko DT, Mamdani M, Alter DA. Lipid-lowering therapy with statins in high risk elderly patients: the treatment-risk paradox. JAMA 2004;291:1864-970.

9. Petrella RJ, Merikle E, Jones J. Prevalence and treatment of dyslipidemia in Canadian primary care: a retrospective cohort analysis. Clin Ther 2007;29: 742-50.

10. Rapezzi C, Biagini E, Bellis P, et al. Exploring the gap between National Cholesterol Education Program guidelines and clinical practice in secondary care: results of a cross-sectional study involving over 10000 patients followed in different specialty settings across Italy. J Cardiovasc Med 2008; 9:878-87.

11. Langer A, Tan M, Goodman SG, Gregoire J, Lin PJ, Mancini GBH, Stone JA, Wills C, Spindler C, Leiter LA GOAL Canada: Physician Education and Support Can Improve Patient Management CJC Open 2020;2:49-54.

12. Leiter LA, Berard L, Bowering K, et al. Type 2 Diabetes Mellitus Management in Canada: Is It Improving? Can J Diabetes 37 (2013) 82e89

13. Goodman SG, Langer A, Bastien NR, et al. Prevalence of dyslipidemia in statin treated patients in Canada: results of the Dyslipidemia International Study (DYSIS). Can J Cardiol 2010;26:e330e5.

14. Chen G, Farris MS, Cowling T, Colgan SM, Xiang P, Pericleous L, Rogoza RM, Tai MH, Anderson T. Treatment and Low-Density Lipoprotein Cholesterol Management in Patients Diagnosed With Clinical Atherosclerotic Cardiovascular Disease in Alberta. Can J Cardiol. 2019 Jul;35(7):884-891

15. Grima DT, Leiter LA, Goodman SG, Attard CL, Chow CM, Langer A. How Many Cardio vascular Events Can Be Prevented With Optimal Management of High-Risk Canadians? Can J Cardiol 2008;24(5):363-68.

17. Cannon CP, Blazing MA, Giugliano RP, et al. Ezetimibe added to statin therapy after acute coronary syndromes. The New England journal of medicine. 2015

18. Sabatine MS, Giugliano RP, Keech AC et al. Evolocumab and Clinical Outcomes in Patients with Cardiovascular Disease. N Engl J Med 2017;376:1713-22

19. Schwartz GG, Szarek M, Bhatt DL et al. The ODYSSEY OUTCOMES Trial: Topline Results. Alirocumab in Patients After Acute Coronary Syndrome. Presented at the American College of Cardiology Annual Scientific Sessions March 10, 2018

20. Langer A, Tan M, Cieza T et al. Can Clinical Reminder Help Optimize the Use of Secondary Prevention Therapies in Non-ST Elevation Acute Coronary Syndrome? Int J Cardiol Cardiovasc Med 2017;1:1-5..

21. Katz PM, Mendelsohn AA, Goodman SG, Langer A, Teoh H, Leiter LA, Use of a Treatment Optimization Algorithm Involving Statin-Ezetimibe Combination Aids in Achievement of Guideline-Based Low-Density Lipoprotein Targets in Patients With Dyslipidemia at High Vascular Risk Guideline-Based Undertaking to Improve Dyslipidemia Management in Canada (GUIDANC). Can J of Cardiol; 2011(27):138-145. 
22. Tsang JLY, Mendelsohn A, Tan MKK, et al. Discordance between physicians' estimation of patient cardiovascular risk and use of evidence-based medical therapy. Am J Cardiol 2008;102:1142-1145

23.Rogers AM, Ramanath VS, Grzybowski M, et al The association between guideline-based treatment instructions at the point of discharge and lower 1-year mortality in Medicare patients after acute myocardial infarction: the American College of Cardiology's Guidelines Applied in Practice (GAP) initiative in Michigan. Am Heart J. 2007;154:461-469.

24. Arnold SV, Spertus JA, Masoudi FA, et al Beyond Medication Prescription as Performance Measures. J Am Coll Cardiol 2013;62:1791-1801

25. Kucher N, Koo S, Quiroz R, Cooper JM, Paterno MD, Soukonnikov B, Goldhaber SZ. Electronic alerts to prevent venous thromboembolism among hospitalized patients. N Engl J Med. 2005;352(10):969-77. 26. Stephen J. Nicholls, MBBS, $\mathrm{PhD}^{1,2}$; Rishi Puri, MBBS, $\mathrm{PhD}^{2}$; Todd Anderson, MD ${ }^{3}$, Steven E. Nissen, $\mathrm{MD}^{2}$ et al. Effect of Evolucomab on Coronary Disease Progression in Statin Treated Patients. JAMA. 2016; 16(22): 2373-2384.

27. ESC/EAS task force: 2019 Guidelines for the management of dyslipidemias; Eur. Soc. Of Cardiology; Jan 1 2020: 41(1)

28. Cannon C, Blazing M. Ezetimibe add to Statin therapy after Acute Coronary Syndromes. N Eng J Med $2015 ; 372: 2387-2397$

29. Shah BR, Hux JE, Laupacis A, Zinman B, van Walraven C. Clinical Inertia in Response to Inadequate Glycemic Control: Do Specialists Differ From Primary Care Physicians? Diabetes Care 2005 Mar;28(3):6006 .

\section{DISCLOSURES:}

AL has received on behalf of the Canadian Heart Research Centre research grant support from Actelion, Amgen, Bayer, BMS, Merck, Novo Nordisk, Pfizer, Servier and Sanofi .

GBJM has received grants and/or honoraria from Amgen, Sanofi, HLS Therapeutices, Esperion, Astra Zeneca, Bayer, Boehringer Ingelheim, Eli Lilly, Janssen/Johnson \& Johnson, Novartis, Novo Nordisk.

LAL has received research grant support from Astra Zeneca, Amgen, Kowa, The Medicines Company, and Sanofi. He has also served as a consultant for Astra Zeneca, Amgen, Esperion, HLS, Merck, The Medicines Company, and Sanofi

JG has received speaker/consulting honoraria from Amgen, AstraZeneca, Bayer, Boehringer Ingelheim, Bristol Myers Squibb, Eli Lilly, Ferring Pharmaceuticals, HLS Therapeutics, Janssen/Johnson \& Johnson, Merck, Novartis, Novo Nordisk, Pfizer, Sanofi, Servier, Sunovion;

SGG has received Research grant support (e.g., steering committee or data and safety monitoring committee) and/or speaker/consulting honoraria (e.g., advisory boards) from: Amgen, AstraZeneca, Bayer, Boehringer Ingelheim, Bristol Myers Squibb, CSL Behring, Daiichi-Sankyo/American Regent, Eli Lilly, Esperion, Ferring Pharmaceuticals, GlaxoSmithKline, HLS Therapeutics, Janssen/Johnson \& Johnson, Merck, Novartis, Novo Nordisk A/C, Pfizer, Regeneron, Sanofi, Servier; and salary support/honoraria from the Heart and Stroke Foundation of Ontario/University of Toronto (Polo) Chair, Canadian Heart Research Centre and MD Primer, Canadian VIGOUR Centre, Duke Clinical Research Institute, New York University Clinical Coordinating Centre, and PERFUSE Research Institute.JAS has received research support from Sanofi and has served as a consultant and/or speaker for Astrazeneca, Amgen, Bayer, HLS Therapeutics, Lilly, Novartis, Novo-Nordisk, and Sanofi.

Mary Tan has no disclosures.

PJL has been a consultant or speaker for AstraZeneca, Boeringher Ingelheim, Bayer, Eli Lilly, Merck, Sanofi, Amgen, Novo Nordisk, GSK and HLS Therapeutics 


\section{Hosted file}

Table 1.pdf available at https://authorea.com/users/364054/articles/484615-does-managementof-lipid-lowering-differ-between-specialists-and-primary-care-insights-from-goal-canada

\section{Hosted file}

Figure 1.pdf available at https://authorea.com/users/364054/articles/484615-does-managementof-lipid-lowering-differ-between-specialists-and-primary-care-insights-from-goal-canada

\section{Hosted file}

Figure 2.pdf available at https://authorea.com/users/364054/articles/484615-does-managementof-lipid-lowering-differ-between-specialists-and-primary-care-insights-from-goal-canada

\section{Hosted file}

Figure 3.pdf available at https://authorea.com/users/364054/articles/484615-does-managementof-lipid-lowering-differ-between-specialists-and-primary-care-insights-from-goal-canada

\section{Hosted file}

Figure 4.pdf available at https://authorea.com/users/364054/articles/484615-does-managementof-lipid-lowering-differ-between-specialists-and-primary-care-insights-from-goal-canada 